\title{
A PIEDADE SOCRÁTICA SEGUNDO GREGORY VLASTOS
}

\section{Guilherme Domingues da Motta* * Universidade Católica de Petrópolis.}

RESUMO: O presente estudo tem por objetivo apresentar e discutir a abordagem que Gregory Vlastos faz da piedade socrática, uma abordagem que tem o mérito de extrair tanto do Eutífron quanto da Apologia de Sócrates de Platão as premissas fundamentais desse problema, para só então explorar as suas consequências. Estas consequências podem surpreender o leitor na medida em que revelam o caráter subversivo das concepções socráticas explícitas e implícitas nesses textos. A tese central de Vlastos, segundo a qual Sócrates promove uma racionalização do divino, fica bem fundamentada, apesar de haver certo "exagero" na maneira unilateral como ele faz derivar a concepção socrática sobre o divino da moralidade humana. A coragem com que expõe as premissas e consequências dos textos leva ainda o leitor a reconhecer em Platão um autor cuja honestidade intelectual e coragem são patentes. Fica claro que o filósofo não escamoteia as posições subversivas de Sócrates em matéria religiosa, assumindo o risco de prejudicar a defesa do mestre frente ao julgamento da posteridade. $\mathrm{O}$ que parece justificar esse risco é a disposição de assumir a defesa intelectual dessas posições mesmo em seu caráter subversivo, intenção que fica plenamente confirmada no restante de sua obra e, principalmente, na República.

PALAVRAS-CHAVE: Platão; Gregory Vlastos; piedade socrática.

PIETY ACCORDING TO GREGORY VLASTOS

\begin{abstract}
The approach of Gregory Vlastos on Socratic piety has the merit of extracting both from Plato's Euthyphro and Apology of Socrates the fundamental premises and only then fully explore its consequences. This may surprise the reader as it reveals the subversive character of Socratic conceptions on religion explicit and implicit in these texts. His central thesis according to which Socrates promotes a rationalization of the divine is well grounded despite some exaggeration in arguing for an unilateral derivation of Socrates' conception of the divine from human morality. The courage with which he exposes the assumptions and consequences of the texts leads the reader to recognize in Plato an author whose intellectual honesty and courage is evident. It remains clear that the philosopher is not striving to conceal the Socrates' subversive positions in religious matters, taking the risk of jeopardizing a defense
\end{abstract}


of his master to the eyes of posterity. What seems to justify the taking of that risk is the will to engage in the intellectual defense of these points even if they are subversive, a intent which is fully confirmed in the rest of his work, especially in the Republic.

KEYWORDS: Plato; Gregory Vlastos; Socratic piety.

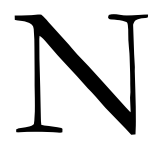

o texto que dedica ao tema da piedade socrática, e que aparece na sua versão final em Socrates, Ironist and Moral Philosopher, ${ }^{1}$ Gregory Vlastos estabelece com clareza, honestidade intelectual e originalidade a concepção socrática sobre o divino que se pode extrair dos diálogos do Platão. Porém, adicionalmente, pela maneira como explicita certos aspectos da abordagem platônica do tema, sua interpretação pode levar o leitor a reconhecer a mesma honestidade em Platão como autor dos diálogos em que Sócrates aparece como personagem.

Vlastos, pela paixão e engajamento com que escreve sobre Sócrates, e pela posição que assume quanto à possibilidade de se extrair dos diálogos de Platão um retrato do Sócrates histórico, pode mesmo ser confundido com um dos muitos apologistas de Sócrates.

Platão pertenceu, sem dúvida, ao número desses, e poder-se-ia suspeitar que o autor dos diálogos subordine as palavras que põe na boca de Sócrates a um projeto apologético que findaria por escamotear elementos que pudessem macular a imagem do mestre, principalmente quando se tem em conta a acusação formal movida contra Sócrates, a saber, a de corromper a juventude e incorrer em impiedade. Porém, é o contrário disso que se pode aduzir de um exame cuidadoso dos textos. O que se encontrará é, antes, um Platão disposto a retratar Sócrates sem interpor qualquer espécie de véu que pudesse amenizar os traços de sua personalidade ou de seu pensamento, arriscando-se, inclusive, a de certo modo justificar a acusação que ele sofreu. A razão dessa atitude parece estar na convicção de Platão de que as posições de Sócrates poderiam continuar a ser defendidas e esclarecidas para além do seu julgamento e morte.

Se são levados em consideração três textos relacionados ao julgamento e condenação de Sócrates, a Apologia, o Críton e o Eutífron, podem-se observar tanto o aspecto apologético quanto o comprometimento com a verdade, sendo a abordagem dos três textos em conjunto a única capaz de fornecer uma visão mais precisa da concepção socrática de piedade.

Assim, se Sócrates na Apologia constrói um argumento de defesa forte e coerente, este não pode passar como tendo sido o mais apropriado do ponto de vista retórico, ou seja, como o mais apropriado para atingir a absolvição. Nele, Sócrates faz críticas contundentes aos próprios juízes e assume uma atitude de altivez que beira o desacato. Esses dois últimos aspectos talvez pudessem ser escamoteados numa apologia cuja intenção fosse preservar a qualquer custo a imagem do mestre; contudo, da maneira como são apresentados por Platão, fica no mínimo justificada a irritação dos juízes para com Sócrates.

\footnotetext{
${ }^{1}$ VLASTOS, 1991.
} 
O Criton, por outro lado, como mostra Vlastos (1991, p. 87-108), descreve Sócrates como um cidadão que ama sua cidade e que de modo algum rejeita as suas leis democráticas, tendo preferido viver em Atenas a viver em qualquer outro lugar. ${ }^{2}$

Considerando-se que havia como pano de fundo do julgamento de Sócrates a acusação, não formalmente feita, mas presente nas entrelinhas da $A$ pologia, ${ }^{3}$ de que Sócrates seria pernicioso para a democracia e um formador dos que foram seus inimigos mais ferrenhos, ${ }^{4}$ surge, pois, a pergunta: ao retratar Sócrates com tamanho apreço por Atenas e suas leis, teria Platão, ao escrever o Críton, e Vlastos, ao interpretá-lo, sucumbido à apologia cega, distorcendo favoravelmente a sua imagem? Ora, tal suspeita não se sustenta, pois, como o mostra Vlastos (1994), nada há de incompatível entre o Sócrates que critica a maneira como era conduzida a democracia ateniense e o Sócrates que diz preferir as leis democráticas de Atenas às de qualquer outra cidade: uma coisa é criticar os desvios da democracia ateniense, outra, bem diferente, é condenar em absoluto a democracia como uma forma de constituição fadada a ser corrupta e perniciosa.

É o terceiro diálogo em questão, o Eutífron, o que mais claramente exime tanto Platão, como autor, quanto Vlastos, como intérprete, dessa acusação de parcialidade, sendo também aquele que mais contribui, ao lado da Apologia, para o esclarecimento da concepção socrática de piedade.

No Eutífron, Platão coloca na boca de Sócrates teses no mínimo subversivas sobre religião. Sócrates, em conversa com a personagem que dá o nome ao diálogo, expõe sua incredulidade acerca do que dizem os poetas sobre os deuses, por exemplo, que as divindades mantêm entre si inimizades e que entram em contenda..$^{5}$ A disposição de Platão de levar adiante essa concepção fica clara, como mostra Burnyeat (2002, p. 141), pela própria passividade de Eutífron frente às teses subversivas de Sócrates; é como se Platão pretendesse explorar até as últimas consequências o que poderia ter sido uma posição socrática sobre a religião.

Isso se confirma pelo tratamento dispensado à questão na República, já que os modelos que foram estabelecidos nessa obra para a composição poética cujo objeto é o divino vêm afinados com os questionamentos socráticos retratados no Eutífron, podendo-se dizer que representam um aprofundamento da visão defendida por Sócrates neste diálogo. ${ }^{6}$

É claro que estes aspectos do Eutífron, e mesmo da República, são bastante explorados por Vlastos em sua análise da piedade socrática, mas é sua capacidade de integrar, com agudeza ímpar, a Apologia em sua interpretação que a torna ainda mais esclarecedora e meritória.

\footnotetext{
${ }^{2}$ Cf. Criton 52a-d.

${ }^{3}$ Apologia de Sócrates 32b-33a. Note-se que Sócrates introduz em sua defesa um relato que visa esclarecer um tema que estava fora da acusação formal, sua suposta associação com os trinta tiranos.

${ }^{4}$ Cf. Xenofonte, Memoráveis I, 2, 9.

${ }^{5}$ Eutifron 6a-c. Sobre o caráter subversivo dessas afirmações e suas consequências, cf. VLASTOS, 1991, p.166; BURNYEAT, 2002, p. 133-144; McPHERRAN, 2002, p. 162-189.

${ }^{6}$ Cf. República 376e-383c.
} 
No texto que dedica ao tema da piedade socrática, Vlastos (1991, p.157) procura mostrar que não há contradição entre o comprometimento de Sócrates em tomar o argumento racional como árbitro final de suas pretensões sobre a verdade no âmbito moral e, ao mesmo tempo, sua disposição para obedecer aos comandos que lhe advêm de canais sobrenaturais. Vlastos pavimenta o caminho para sua demonstração estabelecendo uma analogia entre o que faz Sócrates em matéria de religião e o que fizeram os fisiólogos jônios. Segundo Vlastos, estes últimos não eliminaram a noção de divino, mas a submeteram à razão. Sobre essa concepção dos jônios, escreve ele:

O que é obrigatório para que a divindade tenha um lugar na realidade é apenas que ela seja naturalizada, e, com isso, racionalizada; que seja associada com o caráter ordenado da natureza e não com os rompimentos de sua ordem, como continuou a ser para a grande maioria dos gregos (VLASTOS, 1991, p. 159, tradução própria).

Segundo Vlastos, Sócrates não precisou nem isolar sua fé religiosa de seu comprometimento com a razão, nem abandonar sua investigação sobre a moral em favor de uma especulação física ou metafísica, pois o caminho que tomou não foi exigir de seus deuses que se adequassem a critérios metafísicos, mas sim a critérios morais. Sobre esse ponto, escreve Vlastos:

Os jônios racionalizaram a divindade ao torná-la natural. Do ponto de vista que admite o sobrenatural, que é por eles rejeitado, Sócrates toma uma posição análoga: ele racionaliza os deuses ao torná-los morais. Seus deuses podem ser ao mesmo tempo sobrenaturais e racionalmente compreensiveis, desde que sejam racionalmente morais. Esse, eu proponho, é o seu plano. Dada sua obsessiva concentração em ética, não poderia ter produzido uma teologia natural, mas poderia produzir, e produziu, uma teologia moral, investigando o conceito de deus não além do que é necessário para colocá-lo em conformidade com suas concepções éticas, derivando de sua nova visão sobre a bondade humana normas que vinculam os próprios deuses (VLASTOS, 1991, p. 162, grifo do autor).

O entusiasmo de Vlastos com sua tese se justifica pelo fato de que ela se coaduna perfeitamente com sua concepção de que há um Sócrates histórico sendo descrito nos diálogos de Platão, o qual tem como um de seus traços definidores a concentração na questão moral. $^{7}$

Por outro lado, embora se possa interpretar a experiência de vida de Sócrates como a de um homem que se ocupou de compreender a moralidade humana e que uma vez compreendidos seus aspectos positivos os tenha estendido aos deuses, não parece prudente

\footnotetext{
${ }^{7}$ Cf. VLASTOS, 1991, p. 45-80. Para uma visão contrária à de Vlastos sobre esse ponto, cf. KAHN, 1996. Ver também KAHN, 1992.
} 
excluir que para o homem Sócrates também possa ter ocorrido algo semelhante ao que se dá com a personagem Sócrates nos diálogos de Platão como um todo.

Nesse caso, parece um tanto exagerado dizer que as normas que vinculam homens e deuses tenham sido extraídas da análise da moralidade humana, sem que se considere que Sócrates tenha enxergado também a via inversa, segundo a qual a moral tem uma origem divina. E ele poderia ter vislumbrado tal possibilidade seja porque os preceitos da moralidade são cantados por poetas inspirados, seja porque são inferidos do exame de oráculos e sonhos, duas experiências perfeitamente compatíveis com a experiência de vida de Sócrates.

Por outro lado, poder-se-ia ainda aduzir dos diálogos de Platão a doutrina segundo a qual a moral tem raízes em valores objetivos porque derivados duma natureza, uma realidade metafísica que ultrapassa o homem: a dimensão das Ideias. Que o homem seja capaz de, numa sociedade imoral, "subir" até o conhecimento objetivo da moralidade fundada no divino, parece ser uma possibilidade muito clara para Platão e, de certo modo, um desenvolvimento da herança socrática da busca pelo fundamento. Na República, por exemplo, nas passagens em que apresenta seus moldes para a teologia (citadas por Vlastos para corroborar sua tese), para concluir que os deuses não são causa de mal, Platão parece depender muito mais do que seria a natureza deles do que de um empréstimo de conclusões sobre a moralidade humana. ${ }^{8}$

A questão da piedade nos diálogos platônicos parece admitir ambas as vias: de um lado, a descoberta de valores objetivos e fundados em realidades que ultrapassam o âmbito do humano e, de outro, a possibilidade de que seja reconhecido o valor das normas assim adquiridas, sendo consideradas verdadeiras e boas e, portanto, as únicas compatíveis com a excelência divina. Não parece necessário excluir que mesmo o Sócrates dos diálogos da juventude, ou o Sócrates histórico que inspirou Platão, possa ter transitado entre uma via e outra, enxergando como elas se corroboram mutuamente; de fato, como veremos, a própria interpretação de Vlastos sobre outros pontos parece deixar tal tese pelo menos implícita. De qualquer modo, o cerne da tese de Vlastos sobre a piedade socrática, a ideia de que Sócrates racionaliza os deuses, esclarece perfeitamente, e com ampla fundamentação, o sentido da piedade socrática.

No Eutifron, o que está implícito quando Sócrates coloca em dúvida que os deuses sejam capazes das ações apaixonadas ou "imorais" que lhes atribuem os poetas ou que precisem de sacrifícios como de bens que lhes possam ser ofertados, é uma certa concepção dos deuses como os seres mais excelentes que há. A racionalização está em concluir que seres assim, tão excelentes, não possam ser capazes dos atos que lhes atribuem os poetas, ou que careçam de qualquer oferta humana.

É esse aspecto que é destacado por Vlastos (1991, p. 165) quando mostra que Sócrates presume, que se o conhecimento do bem e do mal acarreta a excelência moral no homem, acarretaria o mesmo para um deus e, dado que a sabedoria do deus ultrapassa grandemente a do mais sábio dos homens, a excelência dos deuses deve ultrapassar em muito a excelência humana.

\footnotetext{
${ }^{8}$ Cf. República 376e-383c.
} 
Também em sua análise do Eutifron o estudioso destaca a passagem em que Sócrates pergunta ao seu interlocutor se a piedade é amada pelos deuses por ser pia ou se é pia porque é amada pelos deuses. Ao optar pela primeira concepção, a piedade é amada pelos deuses por ser pia, Sócrates está, segundo Vlastos (1991, p. 165), presumindo que a piedade é aquilo que ela é independentemente das preferências dos deuses. A piedade, como qualquer outra virtude, tem uma essência própria que é normativa, seja para os homens, seja para os deuses.

Uma outra consequência, ainda de acordo com Vlastos (1991, p. 165), da racionalização do divino por parte de Sócrates é sua conclusão de que se a excelência moral do homem nunca poderá levá-lo a causar o mal a ninguém, o mesmo aplicar-se-á forçosamente aos deuses. O problema que Vlastos (1991, p. 166) identifica nessa concepção socrática da divindade é que, se os deuses da cidade tivessem que observar esses padrões de moralidade, deixariam de ser os deuses aos quais a cidade presta culto e oferece sacrifícios, com todas as consequências, inclusive políticas, que se seguiriam. Desses aspectos da concepção socrática do divino apresentadas por Platão, Vlastos (1991, p. 166) trata de tirar as conclusões: a concepção socrática da divindade bem pode justificar a acusação de impiedade e de corrupção da juventude, pois os deuses "morais" de Sócrates bem poderiam ser considerados deuses que não são os da cidade.

Burnyeat (2002, p.135), seguindo a linha de Vlastos, mostra que no Eutifron as duas acusações que sofreu Sócrates, corrupção da juventude e impiedade, estão diretamente relacionadas; numa passagem em que responde a Eutífron acerca da acusação que lhe faz Meleto, a de corromper a juventude, Sócrates diz: "É absurdo, meu admirável amigo, de se ouvir. Pretende que eu crio deuses, sendo justamente por criar deuses novos e não acreditar nos antigos que ele apresentou a queixa contra mim, segundo declarou".?

Platão, como é patente, parece disposto a indicar ele mesmo ao leitor os motivos pelos quais certas concepções de Sócrates são realmente problemáticas. Não porque deseje que se o considere merecedor da condenação, mas porque quer colocar em questão a própria concepção tradicional de piedade, como continuará a fazer ao longo do referido diálogo e, principalmente, na República. ${ }^{10}$ Não teria sentido colocar na boca de Sócrates no Eutífron, um diálogo cujo tema é tão diretamente ligado ao julgamento de Sócrates, teses que seriam prejudiciais à sua defesa, se ele não tivesse efetivamente feito afirmações semelhantes em vida. ${ }^{11}$ Essa opção de Platão parece indicar que ele deseja despertar a discussão sobre tais teses. Neste sentido a apologia que Platão tem em vista vai muito além do julgamento e de seus méritos; ele consideraria ser necessário colocar em discussão vários aspectos do legado

\footnotetext{
${ }^{9}$ Tradução de Carlos Alberto Nunes, 2007, p. 192.

${ }^{10}$ Cf. República 376e-383c.

${ }^{11}$ Caso não fossem teses defendidas por Sócrates, faria mais sentido que Platão as tivesse colocado na boca da personagem central da República, permitindo a um intérprete como Aristóteles, por exemplo, atribuir essas afirmações ao "Sócrates da República" e não ao Sócrates histórico. Sobre a discussão sobre a historicidade de Sócrates nos diálogos platônicos cf. VLASTOS,1991; KAHN, 1992 ; KAHN, 1996.
} 
socrático, ainda que estes possam ser considerados prejudiciais para a absolvição de Sócrates diante de seu tribunal. ${ }^{12}$

É sobre esses aspectos que Platão volta sua atenção e para cujo debate convoca os “juízes” de Sócrates por toda a posteridade. Desses “juízes”, como de todos os seus leitores, Platão sempre exige uma leitura abrangente e que vá além do dado imediato.

Da análise de Vlastos sobre a piedade socrática, aquilo que mais se destaca quanto à originalidade é o argumento com o qual ele aprofunda a fundamentação da tese de que são conciliáveis a crença de Sócrates na razão e sua disposição a obedecer aos deuses, atestada por suas próprias palavras na Apologia. Vlastos (1991, p. 167-173) defende que não se pode interpretar que Sócrates seja um homem que segue a razão, mas que considera sua crença nos deuses como superior a ela, sendo as ordens divinas o critério último para a ação.

Citando o Fédon 61a, Vlastos (1991, p. 167) mostra que Sócrates parece tomar os sinais divinos que recebe como passíveis de interpretação, a qual ficaria a seu cargo. A passagem em questão é aquela em que Sócrates interpreta seus sonhos como uma advertência divina pela qual os deuses exortá-lo-iam a fazer música. Segundo conta o filósofo, ele primeiro presumiu (bypélabon) que os sonhos continham uma ordem para fazer filosofia, por entender que a filosofia é a mais alta música, mas depois, já na prisão, lhe ocorreu que os sonhos vinham lhe ordenando a fazer música no sentido corrente da palavra. Assim, nesse segundo momento, pareceu-lhe que seria mais seguro não partir dessa vida sem cumprir a ordem divina, compondo versos em obediência ao sonho. Segundo Vlastos (1991, p. 168), pela própria escolha das palavras, Sócrates considera que os sonhos the transmitem um sinal divino suscetível de interpretações alternativas, sendo a escolha entre elas facultada ao intérprete.

$\mathrm{Na}$ mesma linha, a recusa de Sócrates em conferir o título de sábio ao poeta, mencionada na Apologia e justificada no Íon, justificar-se-ia pelo fato de que mesmo não negando o acesso deste à inspiração divina, nega-lhe o conhecimento do sentido da comunicação divina. O que está implícito é que para Sócrates o título de sábio só poderia provir da real compreensão por parte do poeta daquilo que ele profere, ou seja, de um emprego da razão àquilo que sabe por inspiração (VLASTOS, 1991, p. 168). Não é outra coisa o que Sócrates faz, aponta Vlastos, com o próprio oráculo que recebe e cujo tratamento é descrito na Apologia: submete-o à razão crítica para dele extrair a verdade. Sobre essa maneira de agir de Sócrates, Vlastos conclui:

Sua teoria tanto preserva a venerável concepção de que a experiência mântica tem causa divina, quanto aniquila a ameaça dessa concepção à exclusiva autoridade da razão na determinação de questões de verdade ou falsidade (VLASTOS, 1991, p. 171).

Assim, segundo Vlastos, não há paradoxo entre o compromisso incondicional de Sócrates com a razão crítica, não importando a que ela conduza, e seu igualmente

\footnotetext{
${ }^{12}$ Um bom exemplo do quanto argumentos como esse podem ser usados contra Sócrates numa acusação vinda de um autor moderno é o livro, rico em informações, mas equivocado quando ao significado e à interpretação dos diálogos, de I. F. Stone (cf. STONE, 1988).
} 
incondicional compromisso com a obediência de ordens recebidas dos deuses por meio de sinais sobrenaturais. Sobre isso, conclui Vlastos:

Esses dois compromissos não podem conflitar porque é só pelo uso de sua própria razão crítica que Sócrates determina o real significado de qualquer desses sinais (VLASTOS, 1991, p. 171).

Vlastos aplica com grande pertinência essas conclusões à sua esclarecedora interpretação sobre como Sócrates passou do recebimento de um oráculo, segundo o qual era o mais sábio dos homens, à crença de que sua prática em Atenas constituísse missão divina.

Citando a Apologia, Vlastos mostra o quanto a própria linguagem de Sócrates denuncia o recurso à interpretação pessoal para chegar à conclusão de que ele estaria cumprindo uma missão divina, bem como para desvendar o sentido dessa missão. Diz Sócrates em 28e: "O deus me ordenou, como eu supus e presumi, a viver filosofando e examinando a mim mesmo e aos outros". ${ }^{13}$ Vlastos (1991, p. 171-172) entende que o que é fundamental não são as palavras do oráculo ou os sonhos que teve (os quais também são mencionados), mas sim a interpretação que dá a essas palavras e sonhos, a qual só pode decorrer dum exame racional.

Assim, segundo o autor, não seria surpresa que mesmo que o oráculo, ou algum sonho, tivessem explicitamente ordenado a Sócrates que filosofasse, ou examinasse a si mesmo e aos homens de Atenas, ainda assim ele submetesse essa ordem a exame, nem que fosse para certificar-se de que poderia ter sido realmente dada por um deus. Segundo Vlastos (1991, p. 172), teriam sido estas as perguntas de Sócrates: “Tenho eu razão para acreditar que é isso mesmo que o deus quer que eu faça? É ele esse tipo de deus? Qual o seu caráter?"14

Como mostra Vlastos, uma afirmação explícita de Sócrates sobre o caráter do deus e que já implica a racionalização do divino, contra a visão corrente, é aquela que faz em Apologia 21b, referindo-se ao oráculo: "Certamente ele não está mentindo. Isto não seria certo para ele”. Para Vlastos (1991, p. 173), Sócrates só pode ter chegado a essa concepção porque para ele a divindade é invariavelmente boa e incapaz de causar o mal e, sendo enganar os homens um mal que se lhes faz, o seu deus seria incapaz de fazê-lo. Vale a pena citar o restante da interpretação de Vlastos sobre o que defende que esteja implícito na concepção socrática do divino:

E como sua bondade está implicada em sua sabedoria, que éilimitada, sua bondade tem de ser também ilimitada. E como sua boa-vontade é direcionada aos concidadãos de Sócrates, não menos do que ao próprio Sócrates, ele deve desejar que eles ponham a perfeição de sua alma acima de todas suas outras preocupações.

\footnotetext{
${ }^{13}$ Verteu-se aqui para o português a tradução feita por Vlastos do texto da Apologia 28e; ei-la no original: "The god commanded me, as I supposed and assumed, to live philosophizing, examining myself and others." ${ }^{14}$ No original: "Do I have reason to believe that this is work the god wants done by me? Is he that sort of god? What is the character?"
} 
Como poderia o deus fazer valer este seu desejo para eles? Como poderia fazer a todos os atenienses enxergar que "eles devem ter como primeira e maior preocupação para a sua alma que ela seja tão excelente quanto possível??" Ele poderia tê-los enviado sinais com esse fim, sonhos e oráculos em abundância. Mas a menos que eles interpretassem os sinais a partir de crenças verdadeiras, não seriam capaz̧es de lê-los corretamente. E eles não poderiam ter chegado a essas crenças verdadeiras se não estivessem engajados na busca pela verdade moral. Assim, o deus está o impedido de prosseguir. Mesmo sendo poderosíssimo em muitos modos, como de fato é, nesta questão ele é impotente para levar adiante, com suas próprias forças, seu desígnio. ${ }^{15}$

Para Vlastos (1991, pp. 173-174), Sócrates representa esse homem capaz de ler corretamente os sinais e de ajudar o deus e fazer, em seu nome, o benefício desejado por ele para os atenienses, o que ele não poderia fazer sem essa ajuda.

Sendo assim, fica claro que é derivada da razão a crença de Sócrates de que sua prática é um trabalho feito em nome do deus, mesmo que o oráculo não o tenha dito explicitamente. É porque é capaz de perceber que o exame que empreende pela cidade representa um bem, que Sócrates pode concluir que ao manter-se firme na prática do exame presta um serviço ao deus, pois este deseja o bem. Nessa linha, a definição da piedade a que se chega a certa altura do Eutífron, "um serviço prestado ao deus", e conduzida à aporia pela incapacidade de Eutífron de compreendê-la, ganharia, no cotejo com a Apologia, não só confirmação como atingiria seu sentido pleno e poderia bem ser, segundo Vlastos (1991, p. 175-176), a definição da piedade socrática, que resultaria, segundo ele, assim: "piedade é prestar um serviço ao deus para beneficiar os seres humanos".

Vlastos deixa claro que uma fórmula assim é revolucionária e mesmo subversiva, tendo em vista a concepção de religião dos gregos ou qualquer outra concepção em que a magia, negra ou branca, esteja presente. Segundo o autor (VLASTOS, 1991, p. 176), a magia é expurgada da religião socrática e ela só pode ser compreendida como aquela em que os homens se dirigem a deuses que são, por natureza, incansavelmente benevolentes.

Para Vlastos, finalmente, a concepção socrática de piedade traz ainda uma outra marca: ela representaria a libertação duma forma de egocentrismo que é endêmica no próprio eudaimonismo socrático, segundo o qual todas as coisas são meios para se atingir a felicidade, entendida como plenitude do próprio indivíduo. Ao conduzir Sócrates pelo caminho que conduziu, o deus estaria, portanto, beneficiando não só os atenienses, mas o próprio Sócrates, ao colocá-lo em contato com uma compreensão mais elevada da vida. Diz Vlastos:

Na piedade Socrática, aquela ligação entre o nosso bem e o dos outros é tornada não-contingente através da devoção a um deus desinteressadamente benevolente, o qual, sendo já perfeito, não requer de nós qualquer contribuição para seu próprio bem-estar,

\footnotetext{
${ }^{15}$ VLASTOS, 1991, p. 173. Grifo do autor.
} 
mas apenas pede a cada um de nós que faça pelas outras pessoas o que ele mesmo faria por elas se trocasse de lugar conosco. Para as toxinas espirituais presentes na motivação eudaimonista, a elevada religiosidade aqui presente fornece o antídoto." ${ }^{16}$

É inegável a originalidade e o vigor da interpretação de Vlastos sobre a piedade socrática, assim como é inegável que ela a esclarece em muitos aspectos.

Da bem fundamentada tese segundo a qual Sócrates racionaliza o divino, passando pela honesta admissão do caráter subversivo da piedade socrática, Vlastos arrisca-se corajosamente em sua surpreendente conclusão. Porém, o apologista honesto merece apologia e, poder-se-ia dizer em favor dessa sua última tese, fruto de profunda intuição e que só pode ser resultado de enorme dedicação ao texto platônico, que ela se confirma na cidade construída com o lógos na República, na qual a missão do filósofo ainda é conduzir à felicidade e à virtude todos os homens, simplesmente porque essa é sua função, sem esperar por isso qualquer real benefício que porventura já não possua, num genuíno serviço à divindade.

\section{REFERÊNCIAS}

\section{Textos Antigos}

PLATÃO. Critão - Menão - Hípias Maior e outros. Tradução de Carlos Aberto Nunes. 2. ed. revisada. Belém: Universidade Federal do Pará, 2007.

PLATO. Platonis Opera. Recognovit brevique adnotatione critica instruxit Ioannes Burnet. Oxford: Oxford University Press, 1903. (Col. Oxford Classical Texts).

XENOPHON. Memorabilia, Oeconomicus, Symposium, Apology. Translated by E. C. Marchant, and O. J. Todd. London: Harvard University Press, 1923. (Col. Loeb Classical Library, n. 168.)

\section{Textos Modernos}

BURNYEAT, M. F. The impiety of Socrates. In: BRICKHOUSE, T. C.; SMITH, N. (Ed.). The Trial and execution of Socrates: sources and controversies. New York: Oxford University Press, 2002. p. 133-144.

KAHN, C. H., Plato and the Socratic dialogue: The philosophical use of literary form. New York: Cambridge University Press, 1996.

KAHN, C. H. Vlastos' Socrates. Phronesis, v. 37, p. 233-258, 1992.

McPHERRAN, M. L. Does Piety Pay? Socrates on Prayer and Sacrifice. In: BRICKHOUSE, T. C.; SMITH, N. (Ed.). The Trial and execution of Socrates: sources and controversies. New York: Oxford University Press, 2002. p. 162-189.

${ }^{16}$ VLASTOS, 1991, p.177. 
STONE, I. F., O Julgamento de Sócrates. Tradução de Paulo Henriques Britto. Apresentação de Sérgio Augusto. São Paulo: Companhia das Letras, 1988.

VLASTOS, G. Socrates, ironist and moral philosopher. Ithaca/New York: Cornell University Press, 1991. (Col. Cornell Studies in Classical Philosophy, v. 50.)

VLASTOS, G. Socratic Studies. New York: Cambridge University Press, 1994. 